Type of the Paper (Article, Review, Communication, etc.)

\title{
Anomalous Geomagnetic Signal Emphasized Before the Mw8.2 Coastal Alaska Earthquake, Occurred on 29 July 2021
}

\section{Dragoș Armand Stănică}

Department of Electromagnetism and Lithosphere Dynamics, Institute of Geodynamic of the Romanian

Academy, R-020032 Bucharest, Romania,

*Correspondence: armand@geodin.ro; Tel.: Tel.: +40-0788-419-041;

\begin{abstract}
A very strong earthquake of magnitude Mw8.2 struck the coastal zone of Alaska (USA), on July 29, 2021. This earthquake was felt around the Gulf of Alaska, on a wide offshore area belonging to USA and Canada. In order to identify an anomalous geomagnetic signal before the onset of this earthquake, we retrospectively analyzed the data collected on the interval June 17 - July 31, 2021, via internet (www.intermagnet.org), at the two geomagnetic observatories, College (CMO) Alaska and Newport (NEW)-USA, by using the polarization parameter (BPOL) and the strain effect-related to geomagnetic signal identification. Thus, for the both observation sites (CMO and NEW), the daily mean distribution of the BPOL and its standard deviation (STDEV) are carried out using an FFT band-pass filtering in the ULF range (0.001-0.0083Hz). Further on, a statistical analysis based on a standardized random variable equation was applied to emphasize the following: a) the anomalous signature related to Mw8.2 earthquake on the both time series $\mathrm{BPOL}^{*}(\mathrm{CMO})$ and $\left.\mathrm{BPOL}^{*}(\mathrm{NEW}) ; \mathrm{b}\right)$ the differentiation of the transient local anomalies associated with Mw8.2 earthquake from the internal and external parts of the geomagnetic field, taking the NEW observatory as reference. Finally, on the $\mathrm{BPOL}^{*}(\mathrm{NEW}-\mathrm{CMO})$ time series, carried out on the interval 07-31 July, 2021, a very clear anomaly of maximum, greater than 1.2 STDEV, was detected on July 22, with 7 days before the onset of Mw8.2 earthquake
\end{abstract}

Keywords: polarization parameter, standard deviation, Mw8.2 earthquake, CMO and NEW observatories -Alaska

\section{Introduction}

Natural events like earthquakes are inevitable and extremely hard to predict, therefore, the actual major challenge for the geoscience community is to develop specific methodologies able to identify reliable short-term pre-seismic anomalous signals, on the time-scale of weeks, days or hours, that is believed to be the highest priority for social demands in seismic-active countries [1]. Consequently, in the last few decades, the electromagnetic/ geomagnetic signals related to the earthquakes have been identified based on the ground-based and satellite observations techniques. The most known of them are: the European VLF/LF radio network [2]; plasma turbulence in ionosphere prior the earthquakes on the DEMETER registrations [3]; new magnetic index based on vertical geomagnetic variation [4]; ULF magnetic field measurement related to Mw 7.1 Loma Prieta earthquake [5, 6]; geomagnetic diurnal variation associated with the $\mathrm{Mw} 9.0$ Tohoku earthquake [7]; multiple fractal model of pre-seismic electromagnetic phenomena [8]; ULF geomagnetic disturbances related to the earthquakes by using reference data [9]; ULF magnetic disturbances associated with earthquakes [10]; geophysical data possibly associated with the Ms8.0 Wenchuan earthquake [11]; electric and magnetic fields accompanying seismic and volcanic activity [12]; long-range anomalous electromagnetic effect related to Mw9.0 Great Tohoku earthquake [13]; earthquake prediction and precursor [14]; changes of the geoelectric conductivities, which in the real geophysical properties may generate internal electromagnetic effect [15-18]. All these mentioned research ways may supply more useful information about the origin of the different 
pre-seismic anomalous geomagnetic signals related to the major seismic events, what means a more conclusive separation of them. The aim of the present paper, is to emphasize any certain inter-relation between the geomagnetic anomalous geomagnetic signals and Mw8.2 earthquake occurrence in the coastal zone of Alaska - USA, on July 29, 2021, by using the geomagnetic date supplied by the College (CMO) and Newport (NEW) geomagnetic observatories. In order to identify the geomagnetic precursory anomalies, the BPOL(CMO), BPOL(NEW), ABS BPOL ${ }^{*}(\mathrm{CMO}), \mathrm{ABS} \mathrm{BPOL}^{*}(\mathrm{NEW})$, and ABS BPOL*(NEW-CMO) were used.

\section{Materials and Methods}

\subsection{Earthquake location and seismicity}

In conformity with the data offered by Euro Mediterranean Seismic Centre, the

map

some

map presented in Fig.1 reveals both the location of the Mw8.2 earthquake generated on the coastal zone of Alaska (USA) at about 43km depth on July 29, 2021(red full circle), and the placement of the both geomagnetic observatories: College (CMO) and Newport (NEW) (green full circles). To have an idea about the circumstances of this earthquake occurrence, on the above-mentioned map the seismicity from the previous 7 days is presented in the area by means of yellow and brown circles. The present paper tries to show how this activity is reflected in the geomagnetic field variations, by analyzing

geomagnetic monitoring data in the frame of the specific geological circumstances.

Maps view: Seismicity from the previous 7 days in the area $\square$. O Previous $24 \mathrm{~h}$ Previous $48 \mathrm{~h} \quad$ Previous 7 days

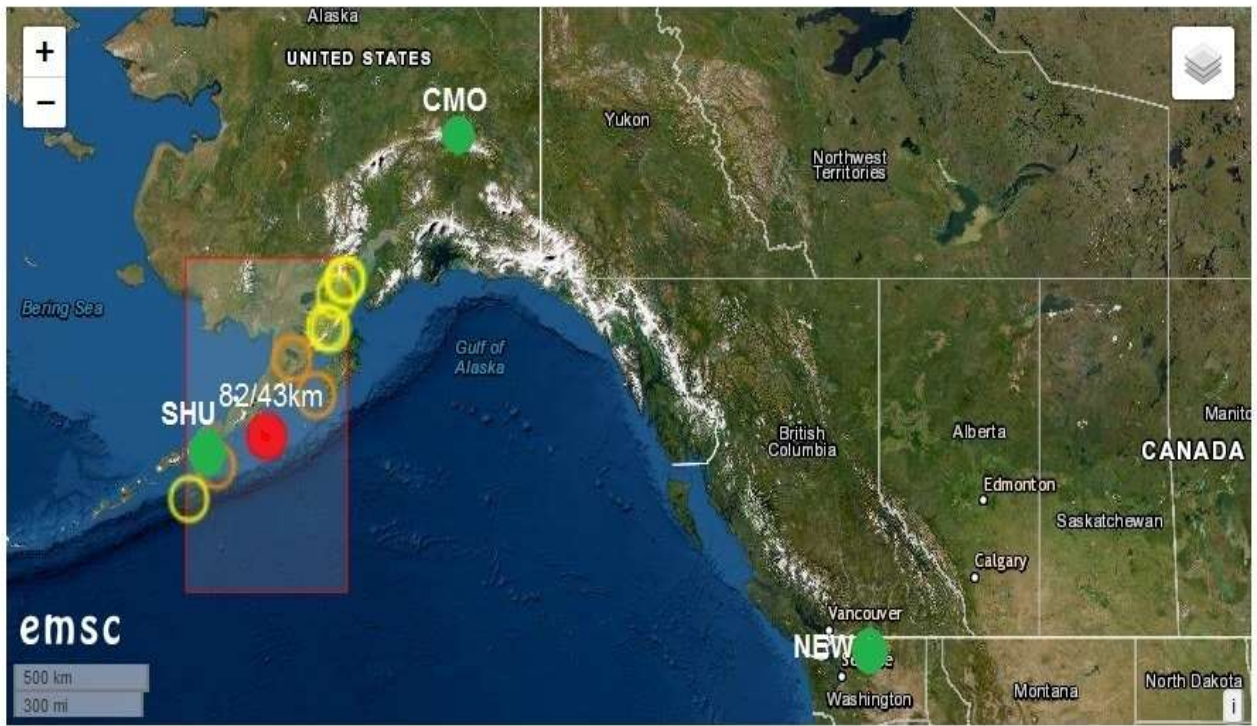

Figure 1. Mw 8.2 earthquake location (red full circle) and the placement of the two

observatories:

CMO and NEW (green full circles)

\subsection{Basic theoretical concepts}

Starting around 2010 year, the geomagnetic monitoring investigations created the possibility to be elaborated a specific methodology that be able to emphasize certain inter- 
relations between the pre-seismic ultralow frequency (ULF) anomalous geomagnetic signature and a major seismic event occurrence [13]. To tackle this methodology some theoretical concepts concerning earthquake generation mechanism had to be taken into consideration, such as: piezomagnetic effect, magneto-hidrodinamic effect and electrokinetic effect [19]. Thus, in order to identify any pre-seismic anomalous signature related to Mw.8.2 earthquake we focused on two relations:

a) Polarization parameter (BPOL) expressed as:

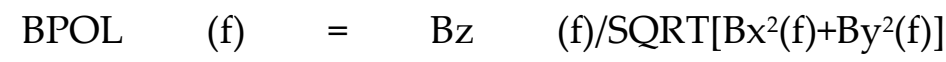

(1)

identification,

(2)

observatory where: $\mathrm{Bx}(\mathrm{f}), \mathrm{By}(\mathrm{f})$ and $\mathrm{Bz}(\mathrm{f})$ are horizontal and vertical components of the geomagnetic field;

b) Range effect of the strain related to the pre-seismic geomagnetic signals due to the Mw8.2 earthquake, Morgunov and Malzev relation [8]:

$$
\begin{array}{llll}
\mathrm{R} & (\mathrm{km}) \quad & 10 & 0.5 \mathrm{M}-0.27
\end{array}
$$

where: $R$ is epicentral distance and $M$ is earthquake magnitude.

According to relation (2) "the strain effect" due to the Mw 8.2 earthquake was felt for $\mathrm{R} \approx 6760 \mathrm{~km}$. As the both epicentral distances are less $(\mathrm{R} \approx 1200 \mathrm{~km}$ for $\mathrm{CMO}$ and $\mathrm{R} \approx 2400 \mathrm{Km}$ for NEW observatory), the identification criteria for an anomalous preseismic signal is fulfilled.

\subsection{Data collection, processing and analysis}

The geomagnetic data (Bx, By and Bz) obtained, via internet (www.intermagnet.com), from the geomagnetic observatories College (CMO) and Newport (NEW), on the interval June 17-July 31, 2021, are used:

a) to carry out the daily mean distribution of the Polarization Parameter (BPOL) and its Standard Deviation (STDEV), Relation (1);

b) to emphasize a possible pre-seismic geomagnetic signature related to the Mw8.2 earthquake to emphasize a possible pre-seismic geomagnetic signature related to the Mw8.2 earthquake, applying a statistical analysis based on relation on relation (3)

$$
\mathrm{BPOL}^{*}=(\mathrm{X}-\mathrm{Y}) / \mathrm{W}
$$

The explanation for $(X, Y, W)$ and $\mathrm{BPOL}^{*}$ may be seen detailed in [20].

c) to separate the pre-seismic anomalous signals from ionospheric and terrestrial variations of the geomagnetic field, the Relation (4) was applied, where the Newport geomagnetic observatory was taken as reference

$$
\mathrm{BPOL}^{*}(\mathrm{NEW}-\mathrm{CMO})=(\mathrm{A}-\mathrm{B}) / \mathrm{C}
$$

A, B, and C signification in relation 4 may be find out in the Refference [20] 


\section{Results}

After the strain effect was determined in conformity with Relation (2) and the identification criteria for an anomalous pre-seismic signal was fulfilled, geomagnetic monitoring data processing by using Fast Fourier Transform- Band Pass Filtering Analysis in the ultralow frequency range $(0.001-0.0083 \mathrm{~Hz})$ will supply the necessary information concerning the daily distribution of the polarization parameter $\mathrm{BPOL}$ for the two $\mathrm{CMO}$ and NEW observatories

\subsection{Time Series distribution for BPOL(COM) and BPOL(NEW)}

The daily mean distribution of the BPOL and its STDEV obtained for the College (CMO) and Newport (NEW) observatories, on the interval 1-31 July, 2021, will supply information regarding the geomagnetic field variations and, most important, will emphasize if their values exceeded the standard limit. This situation may be seen in the Figure (2) and Figure (3), where the daily mean distribution of the BPOL and its STDEV for the CMO observatory and New observatory respectively, is presented in the time interval 1-31 July, 2021.

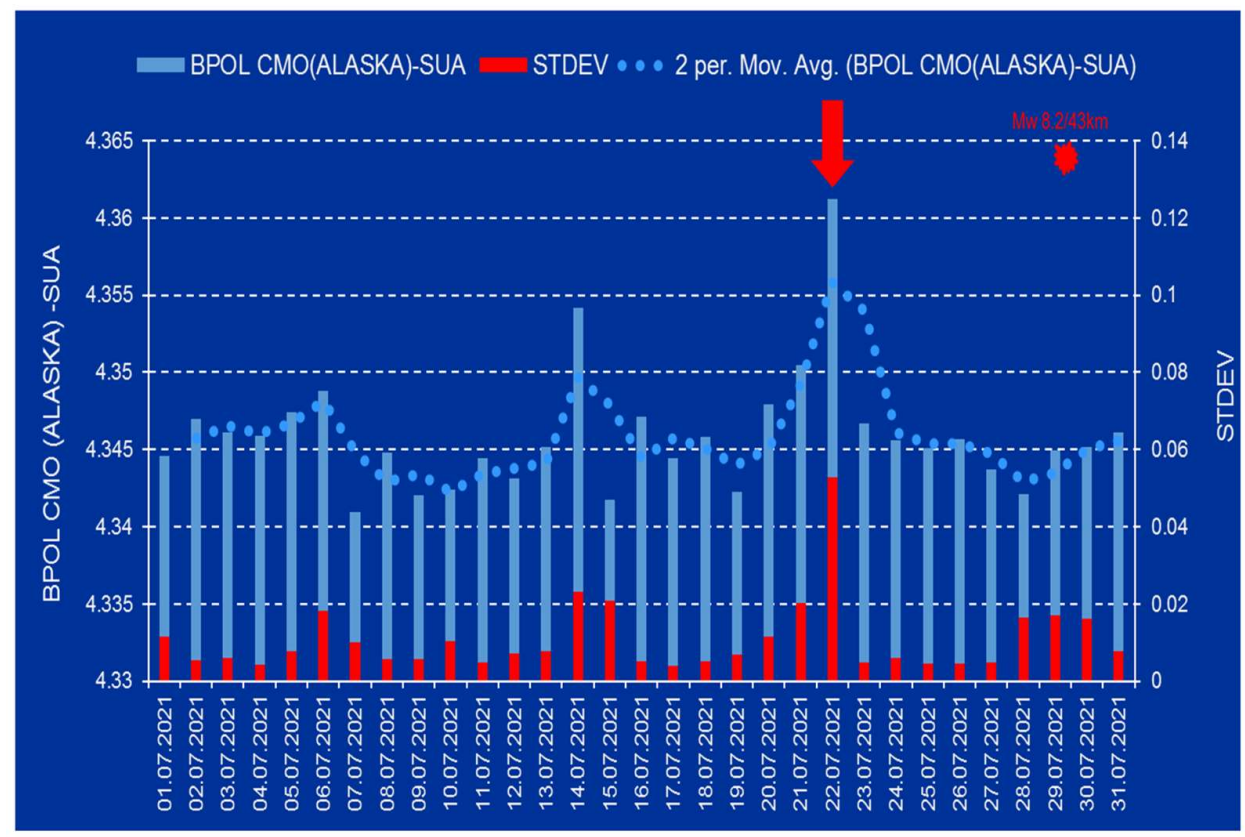

Figure 2. BPOL and STDEV time series for the College (CMO)-USA geomagnetic observatory are presented on the interval 01-31July, 2021; Vertical blue and red bars are daily distribution of the BPOL and its STDEV; Dotted blue line represents 2 days average values of BPOL time series; Red star is Mw 8.2 earthquake on July 29, 2021; Mw8.2/43km (magnitude/depth); Vertical red arrow indicates a pre-seismic anomalous signal generated on July 22. 


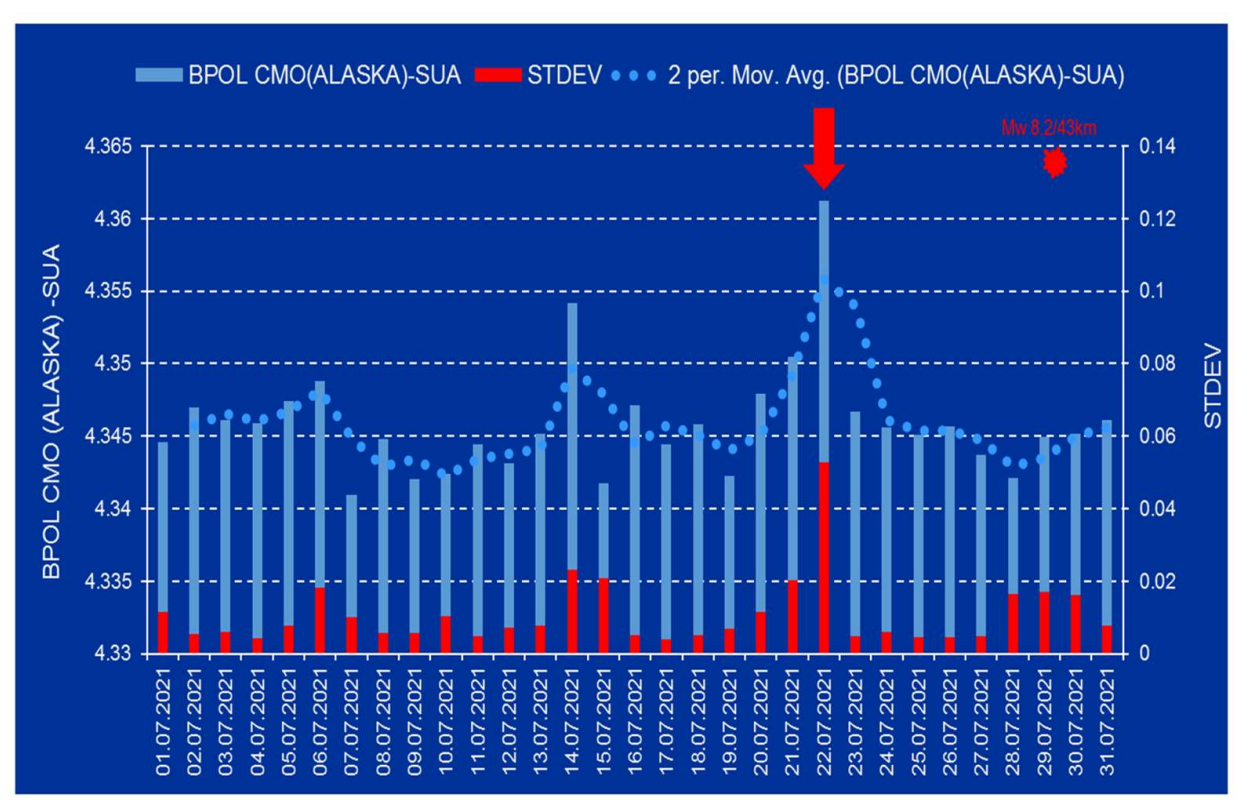

Figure 3.BPOL and STDEV time series for the Newport (NEW)-USA geomagnetic observatory are presented on the interval 01-31July, 2021. Red star is Mw8.2 earthquake on July 29, 2021; Mw8.2/43km (magnitude/depth); Vertical red arrow indicates a pre-seismic anomalous signal generated on July 22

\subsection{Time Series distribution for $B P O L^{*}(C O M)$ and $B P O L^{*}(N E W)$}

The pre-seismic anomalous intervals associated to the Mw 8.2 earthquake are revealed in the following time series: $\mathrm{BPOL}^{*}(\mathrm{CMO}), \mathrm{BPOL}^{*}(\mathrm{NEW})$ and $\mathrm{BPOL}^{*}(\mathrm{NEW}-\mathrm{CMO})$, in conformity

with

Figures (4) , (5) and (6).

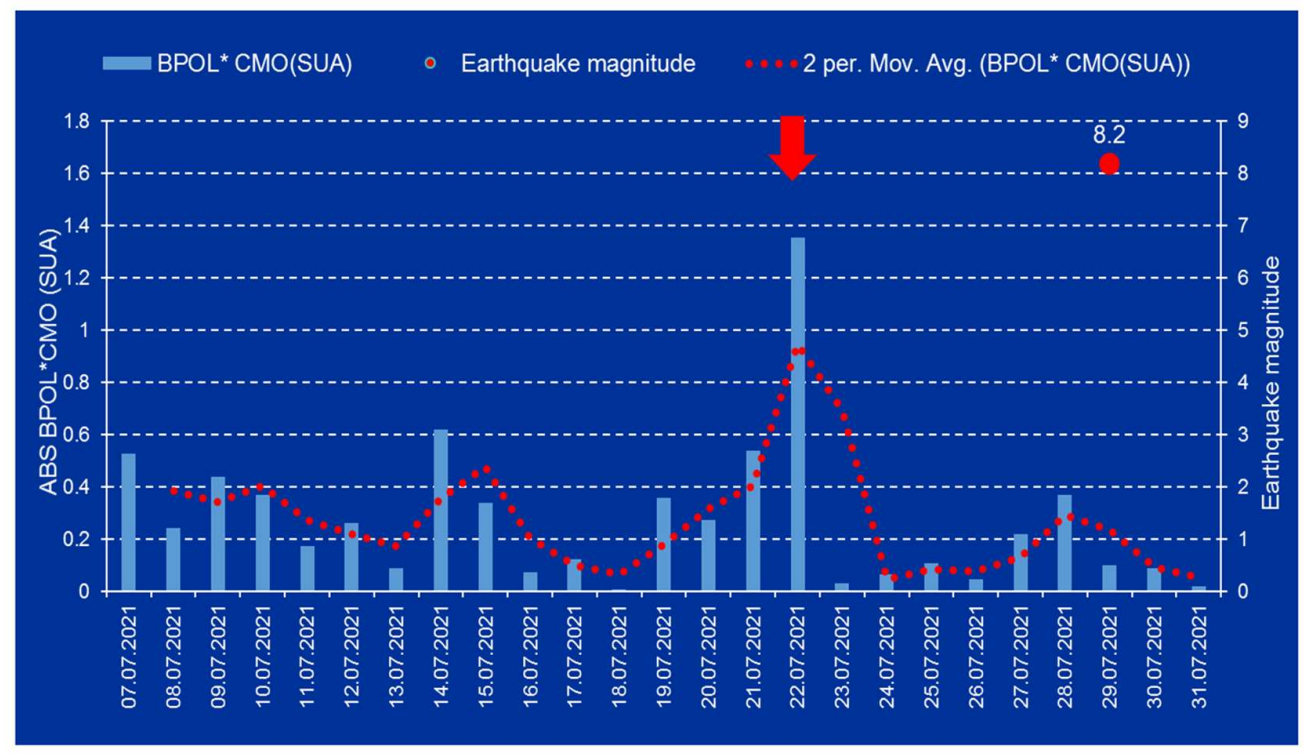

Figure 4. $\mathrm{ABS} \mathrm{BPOL}^{*}$ time series distribution for College (CMO) observatory, represnted by blue bars, on the interval 07-31 July, 2021; Red dotted line represents two days average values of the ABS BPOL* ; Red full circle represents the Mw8.2 eartquake; ABS is BOPL absolute value; Vertical red arrow indicates a pre-seismic anomalous signal generated on July 22. 


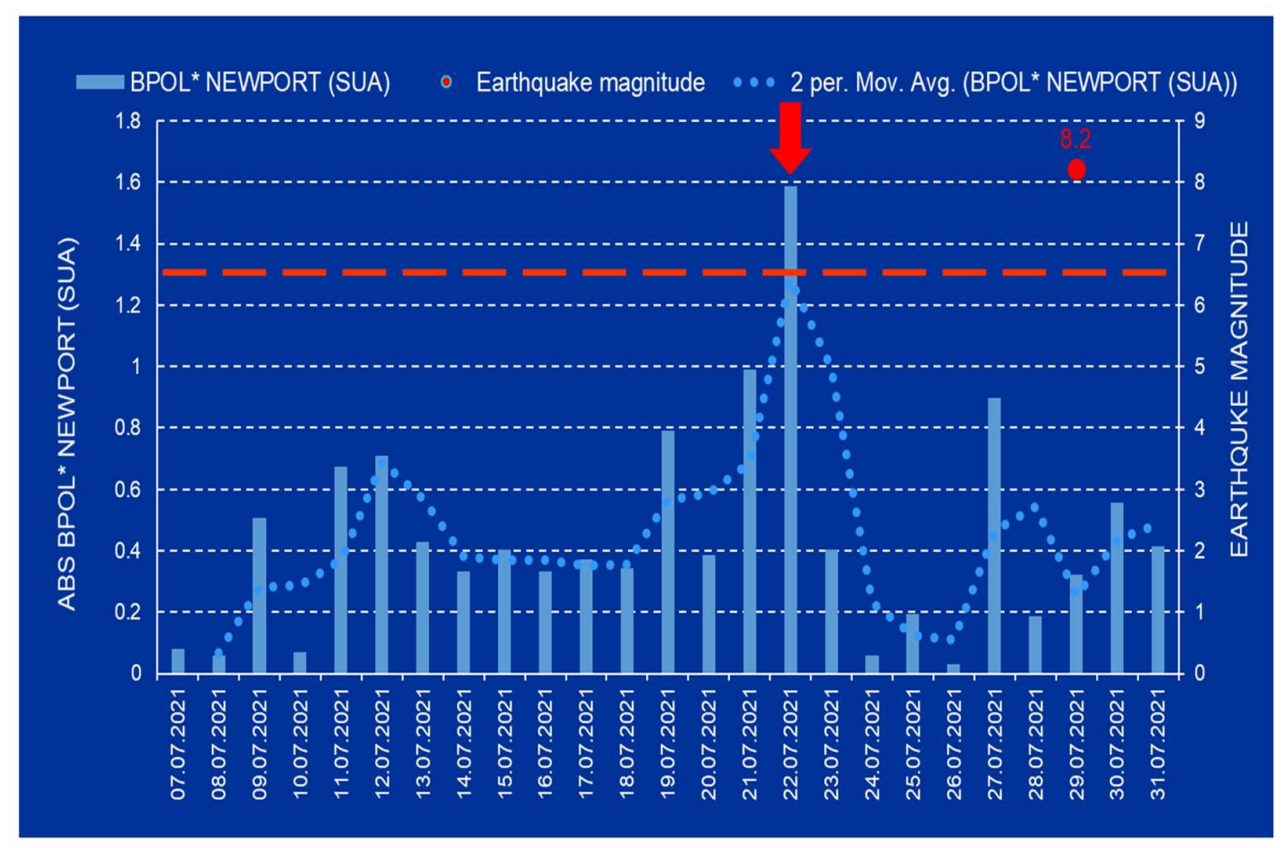

Figure 5. $\mathrm{ABS} \mathrm{BPOL}^{*}$ time series distribution for Newport (NEW) observatory on the interval 07-31 July, 2021. For explanation see Figure 4 caption

\subsection{Time Series distribution for $B P O L^{*}(N E W-C M O)$}

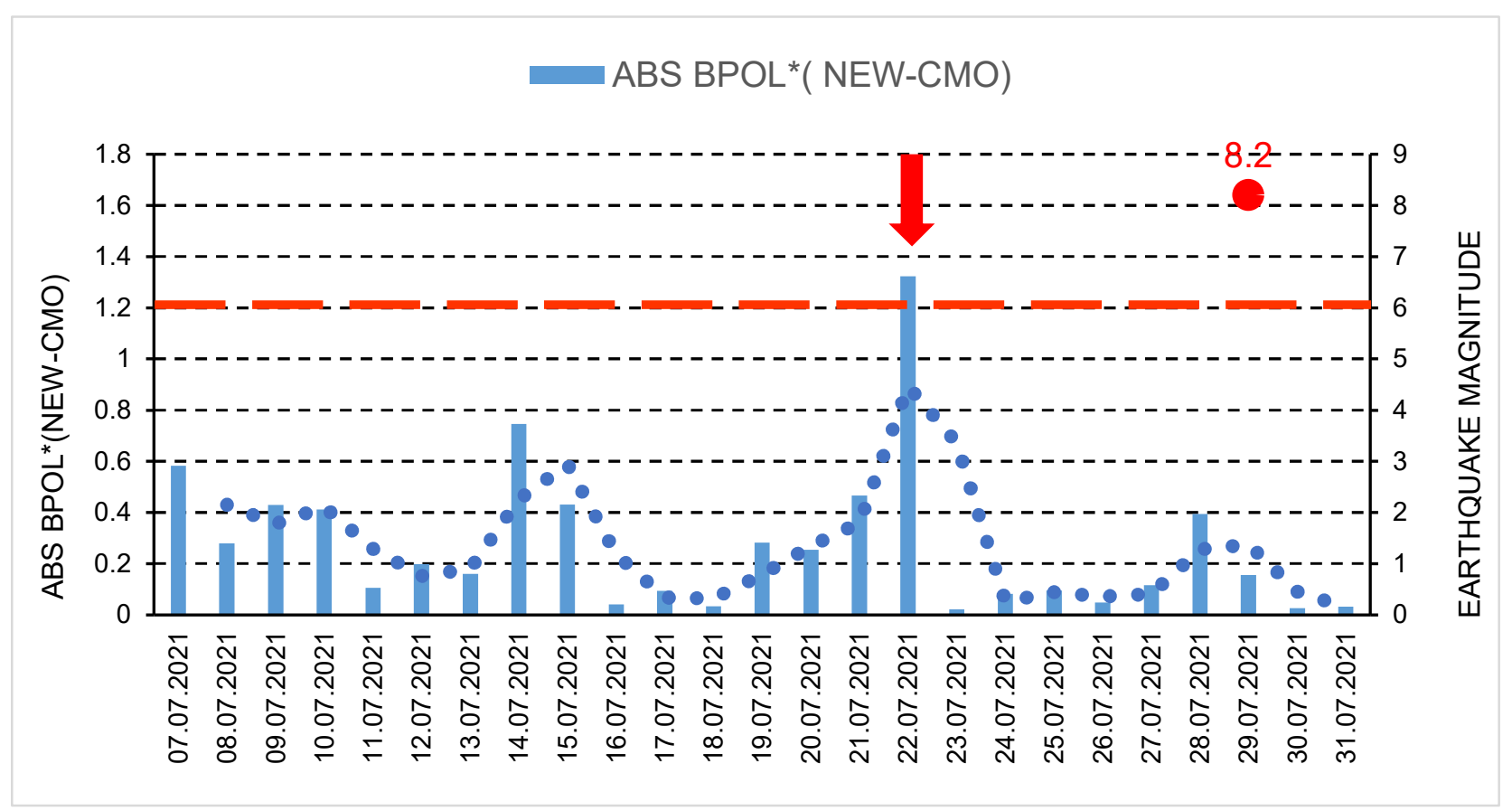

Figure 6. ABS $\mathrm{POL}^{*}(\mathrm{NEW}-\mathrm{CMO})$ time series on the interval 07-31.07.2021; Dashed red line represents the treshold for anomaly using STDEV, used to identify the pre-seismic anomalous signal market on the Figure by the red vertical arrow.

\section{Conclusions}


After the strain effect was determined in conformity with Relation (2) and the identification criteria for an anomalous pre-seismic signal was fulfilled, geomagnetic monitoring data processing by using Fast Fourier Transform- Band Pass Filtering analysis in the ultralow frequency range $(0.001-0.0083 \mathrm{~Hz})$ will supply the necessary information concerning the daily distribution of the polarization parameter BPOL for the two CMO and NEW observatories To take into consideration all the information carried out on the base of the geomagnetic data collected from the College and Newport (Alaska-USA), the final results were very useful emphasizing a precursory geomagnetic anomaly with 7 days before the Mw8.2 earthquake occurrence, as follows:

- The BPOL (CMO) and BPOL(NEW) time series distributions obtained on the interval 01 July - 31 July, 2021 (Figures 2 and 3) highlight an obvious geomagnetic anomaly extended on three days interval, having an apex on 22 July, with 7 days before the earthquake;

- The same precursory signal may be also seen on $\mathrm{ABS}_{\mathrm{BPOL}}^{*}(\mathrm{CMO})$ and $\mathrm{ABS}$ $\mathrm{BPOL}^{*}(\mathrm{NEW})$ carried out on the interval 07 - 31 July, by means of the Relation (3), revealing an asimetric and more narrow geomagnetic anomaly of maxim extended on the interval 18-24 July, having an apex on 22 July, with 7 days before the Mw.8.2 earthquake;

- Information concerning the separation of the pre-seismic signal by the solar storm effect $(\mathrm{Kp})$ was obtained with the Relation (4), where the Newport was taken as reference. The ABS BPOL*(NEW-CMO) time series distribution highlights an apex of the geomagnetic anomalous signal, having 1.2 magnitude on 22 July, identified by means of a threshold for anomaly in Figure 6 (red dashed line).

As final conclusion, it is obviously that the last time serie ABS $\mathrm{BPOL}^{*}(\mathrm{NEW}-\mathrm{CMO})$ demonstrates that the applied methodology, based on the two geomagnetic monitoring sites, might supply usefull information to identify with high accuracy a pre-seismic anomalous signal having a value of 1.3 (Figure 6) on 22 July, 2021, with 7 days before the strong Mw 8.2 earthquake.

For a higher accuracy there is neccesity to use more monitoring sites, so that more directions of the seismic waves propagation be covered, in conformity with specific tectonical features of the investigated area

Auuthor Contributions: not applicable (only one author)

Funding: "This research received no external funding"

Data Availability Statement: “Not applicable" here.

Acknowledgments: In this paper we used the geomagnetic data collected from Geomagnetic Observatories College and Newport- Alaska (USA). We would like to thank the national institutes that support them and INTERMAGNET for promoting high standards of magnetic observatory practice (http://www.intermagnet.org). The author is grateful to the anonymous reviewers for their comments and useful suggestions.

Conflicts of Interest: “The author declares no conflict of interest."

\section{References}

1. Hayakawa, M.; Hobara, Y. Current status of seismo-electromagnetics for short- term earthquake prediction. Geomatics, Nat Haz Risk 2010, 1:115-155.

2. Biagi, P, F.; Maggipinto, T.; Righetti, F.; Loiacono, D.; Schiavulli, L. ; Ligonzo, T.; Ermini, A.; Moldovan, I, A.; Moldovan, A,S.; Buyuksarac, A., Silva, H, G.; Bezzeghoud, M., Contadakis, M, E. The European VLF/LF radio network to search for earthquake precursors: setting up and natural/man-made disturbances. Nat Hazards Earth Syst Sci. 2011, 11: 333-344. doi:10.5194/nhess-11-333-2011 
3. Błęcki, J.; Parrot, M.; Wronowski, R. Plasma turbulence in the ionosphere prior to earthquakes, some remarks on the DEMETER registrations, JAES, 2011, 41:450-458. doi:10.1016/j. jseaes.2010.05.016

4. Ernst, T.; Jankowski, J,; Nowozynski, K. A new magnetic index based on the external part of vertical geomagnetic variation. Acta Geophys 2010, 58 (6):963-972. doi:10.2478/s 11600-010-0014-9

5. Fenoglio, M,A.; Johnston, M, J, S; Bierlee, J, D. Magnetic and electric fields associated with changes in high pore pressure in fault zones: application to the Loma Prieta ULF emissions. J Geophys Res 1995, 100:12951-12958

6. Fraser-Smith, A, C.; Bernardi, A.; Mc Gill, P, R.; Ladd, M, E.; Halliwell, R, A. Villard Jr, O, G. Low frequency magnetic field measurements near the epicenter of the M 7.1 Loma Prieta earthquake. Geophys Res Lett 1990, 17:1465-1468

7. Han, P.; Hattori, K.; Xu, G.; Ashida, R.; Chen, C,H,; Febriani, F.; Yamaguchi, H. Further investigation of geomagnetic diurnal variation associated with the 2011 off the Pacific coast of Tohoku earthquake (Mw9.0). J. Asian Earth Sciences, 2015, 114: 431-434. http://dx.doi.org/10.1016/j.jseas.2015.02.022

8. Morgunov, V, A and Malzev, S,A. A multiple fractal model of pre-seismic electromagnetic phenomena, Tectonophysics, Elsevier 2007, Vol. 431, 61-72, doi: 10.1016/j.tecto.2006.05.030

9. Hattori, K.; Han, P.; Huang, Q. Global variation of ULF geomagnetic fields and detection of anomalous changes at a certain observatory using reference data. Electrical Engineering in Japan, 2013, 182: 9-18. http://dx.doi.org/10.1002/eej.22299

10. Hayakawa, M.; Hobara, Y.; Ohta, K. and Hattori, K. The Ultra-Low-Frequency Magnetic Disturbances Associated with Earthquakes. Earthquake Science, 2011, 24, 523-534. http://dx.doi.org/10.1007/s11589-011-0814-2

11. Huang, Q. Retrospective investigation of geophysical data possibly associated with the Ms8.0 Wenchuan earthquake in Sichuan, China. J. Asian Earth Sciences 2011, 41, 421-427. http://dx.doi.org/10.1016/j.jseaes.2010.04.014

12. Johnston, M, J, S. Review of electric and magnetic fields accompanying seismic and volcanic activity. Surv. Geophys 1997,18: 441-475, http://dx.doi.org/10.2183/pjab.86.257

13. Stanica, D,A.; Stanica, D.; Vladimirescu, N. Long-range anomalous electromagnetic effect related to Mw9.0 Great Tohoku earthquake. Earth Sciences 2015, 4(1): 31-38. doi: 10.11648/j.earth.20150401.13

14. Uyeda, S.; Nagao, T.; Kakogawa, M. Earthquake Prediction and Precursor. In: Encyclopedia of Solid Earth Geophysics, 2011, 5:168-178. http://dx.doi.org/10.107/978-90-481-8702-7_4

15. Freund, F,T. Charge generation and propagation in rocks. J. Geodyn. 2002, 33(4-5), pp.545-572.

16. Park, S, K.; Johnston, M, J, S.; Madden, T, R.; Morgan, F,D.; Morrison, H,F. Electromagnetic precursors to earthquakes in the ULF band - review of observations and mechanisms, Rev. Geophys.,1993, 31, , pp. 117-132.

17. Stanica, D. and Stanica, D, A. Constraints on Correlation Between the Anomalous Behaviour of Electromagnetic Normalized Functions (ENF) and the Intermediate Depth Seismic Events Occurred in Vrancea Zone (Romania), Terr. Atmos. Ocean. Sci., 2010, 21, doi:10.3319/TAO.2009. 09.09.01(T), , pp. 675-683

18. Varotsos, P. The Physics of Seismic Electric Signals, TERRAPUB, 2005, Tokyo

19. Stanica, D, A. and Stanica, D, Possible Correlations between ULF Geomagnetic Signature and Mw6.4 Coastal Earthquake, Albania, Entropy 2021, 23, 233, https://doi.org/10.3390/e23020233 